\title{
Research Progress on Job Burnout of nurses
}

\author{
Huang Wanzhi ${ }^{1}$ \\ ${ }^{1}$ School of nursing, Shenzhen University, China,518060

\begin{abstract}
Job burnout is a syndrome caused by chronic stress at work, which may produce many effects on workers' health. This paper reviews the impact of job burnout on nursing industry, the status quo, influencing factors, assessment tools, improvement measures and future development trends, and puts forward the prospect of job burnout in the future, which is expected to provide a new perspective and guidance for the improvement of job burnout in nursing industry and contribute to people's health and well-being.
\end{abstract}

Keywords: Nurse, Job burnout, Research progress

\section{Introduction:}

Over the years, job burnout has been recognized as an occupational hazard in a variety of human-oriented occupations, such as human services, education as well as health care. These therapeutic or service relationships established by these providers and recipients require sustained and intense personal and emotional contact. The impact of job burnout on individuals and society obviously shows that it is very necessary to take preventive interventions in the work environment and early identify such health conditions. This review intends to introduce the research progress of nursing burnout in detail, so as to improve people's understanding and attention to nursing burnout.

\section{Concept of Job Burnout}

The research on job burnout originates from nursing and service occupations, and the core is the relationship between provider and recipient. Freud Berger[1] first proposed the concept of job burnout in the 1970s. He described job burnout as an exhausted state experienced by people in public service because of three factors: long working hours, too much work as well and too high working strength. Later, Masla [2-5] et al. defined job burnout reported from the following three perspectives: 1) emotional exhaustion, that is, they have no energy, no enthusiasm for work, and they feel that their emotions are in an extremely fatigue state; 2 ) depersonalization, that is, keep a distance between oneself and the working object deliberately, and hold an indifferent and ignoring attitude towards the working object and the environment; 3) low sense of personal achievement or low efficiency (i.e., feeling of personal or professional inadequacy and decline in productivity and coping skills), and they thought that job burnout was a long-term response to inert emotion, interpersonal and work stress in work.

\section{The Influence of Job Burnout on Nursing Industry}

At present, numerous studies have indicated that job burnout is associated with some health problems (such as increased drinking $)^{[6]}$, sleep disorders ${ }^{[7]}$, depression ${ }^{[8]}$, sedentary and obesity ${ }^{[9]}$, and musculoskeletal pain ${ }^{[10]}$, and it has had an important impact on human health, especially in the nursing industry.

The studies conducted by Du Yanqiu and Sun Xiaojie ${ }^{[11,12]}$ et al show that job burnout is associated with a variety of physical body and psychological aspects of mental health. As nursing staff have been working under high pressure for a long time, they are prone to suffer from the following pains, including depression, irritability, anxiety, drowsiness, insomnia, anxiety, trance, endocrine disorders, headache, chest distress, and they may even have acute diseases, such as shock, myocardial infarction, etc, which confirmed that job burnout can produce a very important influence on various aspects of nurses.

In the research on the impact on nursing personnel, the study of Wang Aiwu et al. ${ }^{[13]}$ indicated that the degree of job burnout of nurses is directly proportional to the humoral immunity in the body. The emotional investment, complexity and high difficulty of jobs with high load, long working hours and pressure have an inhibitory effect on the immune function of nursing staff, making nursing staff more prone to suffer from diseases and affecting the quality of care. In addition, in the study carried out by $\mathrm{Xu}$

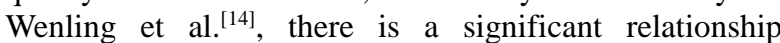
between nurses' mental health and job burnout. The higher the degree of job burnout is, the lower the degree of mental health will be, which will also aggravate the deterioration of physical health.

Impact on social and medical aspects: Job burnout will affect the quality of each nursing staff's work, including lower productivity, small mistakes, forgetfulness, declined job satisfaction, increased medical accident probability and the probability of adverse events of nursing staff ${ }^{[15]}$. When job burnout is serious, it will also lead to a decreased sense of nurses' professional benefit ${ }^{[16]}$, which seriously affect nurses' professional identity, enhance their 
demission intention. In the long run, it will influence hospitals' order and affect the hospitals' overall medical level and even the region ${ }^{[17]}$.

\section{The Current Situation of Job Burnout of Nursing}

\subsection{Overseas research status}

Over the years, job burnout has been popular among nursing staff in various countries and regions, and more and more people begin to pay attention to this phenomenon ${ }^{[18,19]}$. The studies on nursing job burnout have been carried out abroad for more than 30 years, and a researcher has found that the incidence of fatigue syndrome in general occupation groups and nurses is $0.2 \%$ and $1.1 \%$, respectively ${ }^{[20]}$. A study on job burnout and job satisfaction of in-service nurses in 1406 hospitals in 9 countries from 1999 to 2009 [21] showed that, except Germany, job burnout wasn't optimistic in the remaining 8 countries, among which, 33\% 60\% of occurrence rate of nursing job burnout happens in Japan and South Korea. In addition, the study also indicated that the majority of nurses who were surveyed were dissatisfied with their jobs, accounting for $20 \%$, and even $60 \%$ in Japan. According to the study of Nantsupawat et al. ${ }^{[22]}$, Thailand also has a high incidence of job burnout, and $41 \%$ of Thai nurses suffer from job burnout. A study which used the MBI job burnout questionnaire ${ }^{[23]}$ showed that, among 818 registered nurses in South Africa, $34.6 \%$ were at a high level of burnout. In addition, some scholars ${ }^{[24]}$ used Maslach Burnout Inventory to investigate the burnout level of 676 nurses working in Spanish hospitals. According to the survey, the score of the three dimensions in the scale was emotional exhaustion (EE): 17.96 \pm 10.97 , with an incidence rate of job burnout of $21 \%$; depersonalization (DP): $6.56 \pm 5.57$, with an incidence of job burnout of $30 \%$; personal accomplishment (PA): $36.81 \pm 8.52$, with an incidence rate of job burnout of $44 \%$. To sum up, the current level of job burnout is obviously high in foreign countries, which needs to be paid great attention by hospitals and nurses themselves.

\subsection{Domestic present status}

The domestic researches on nurses' job burnout began in 2000. According to the current research ${ }^{[25]}$, the situation of' nurses job burnout in China isn't optimistic. Studies show that $30 \%$ of domestic nurses have varying degrees of emotional failure, and the proportion of severe emotional failure is $8.2 \%$. In addition, more than $12 \%$ of in-service nurses in China show varying levels of depersonalization, and the proportion of reduced sense of personal achievement is more than $12 \%$. It can be seen that the level of job burnout of nurses in China is as serious as that in foreign countries, which also needs to be paid attention to.

\section{Factors Influencing Job Burnout of Nurses}

Imbalance between job demands and job skills, lack of job control, imbalance in reward for efforts (differences between resources, expectations and job realities), and chronic job stress are major risk factors for burnout or other work-related mental health impairment ${ }^{[26]}$. The influencing factors of nurses' job burnout are into individual and organizational factors. Individual factors include demographic variables such as age, professional title, gender, education background, individual characteristics and coping styles, while organizational factors include hospital environment, social support and department management. These factors play an important role in nurses' job burnout.

\section{Evaluation Tools for Nurses' Job Burnout}

The preliminary research on job burnout is exploratory and mainly depends on qualitative techniques. Because the earliest researchers came from social psychology and clinical psychology, they were attracted to ideas in these fields. As the characteristics of job burnout become clearer, researchers have proposed various measures based on different assumptions about job burnout, many of which rely on measuring the apparent validity of items or statements. The first job burnout scale based on psychometric research items is the Maslach Burnout Inventory $(\mathrm{MBI})^{[27,28]}$. MBI was specifically designed to assess three dimensions of burnout experience, which emerged from earlier qualitative studies. Meanwhile, it is considered a standard tool for research in this field and has been translated and validated in many languages ${ }^{[29]}$. In contrast, other preliminary measures of job burnout only focus on the dimensions of emotional exhaustion ${ }^{[30,31]}$.

In addition, the Bergen Burnout Inventory $(\mathrm{BBI})^{[32]}$ evaluates the three dimensions of job burnout: job emotional exhaustion, depersonalization of work, as well as a sense of inadequacy in work. Oldenburg Burnout Inventory $(\mathrm{OLBI})^{[33]}$ evaluates the two dimensions of fatigue and disengagement. Other criteria for emotional exhaustion focus only on fatigue, though they distinguished various aspects of fatigue. For example, Shirom-Melamed Burnout Measurement (SMBM)[34] distinguishes between physical fatigue, emotional exhaustion and cognitive fatigue; Copenhagen Burnout Inventory $(\mathrm{CBI})^{[35]}$ distinguishes physical and mental exhaustion.

Some measures also add new dimensions to the concept of job burnout. For example, the Spanish burnout list consists of four components, including enthusiasm for work, psychological exhaustion, laziness and guilt ${ }^{[36]}$. At the same time, some researchers were concerned that more neutral wording meant that human service personnel had 
lost specific interpersonal problems, so they developed a new measurement method for interpersonal tension ${ }^{[37]}$. Whether these additional factors are important components of job burnout itself or whether they evaluate the experiences or conditions that come with the job burnout experience is still an question to be solved.

\section{Current Measures to Improve Nurses' Job Burnout}

The applicability of job burnout research promotes people to call for effective interventions. More and more researchers are working on this, but there are relatively few systematic studies. Various intervention strategies have been proposed, and some are trying to treat burnout after it has occurred, while others focus on how to prevent it. The prevention and reduction of job-related burnout is not only related to the quality of life of those who are affected or at risk, but also very important for preventing economic losses caused by absenteeism and separation. From an individual perspective, the main focus of research on reducing job burnout is using educational interventions to improve individuals' ability to cope with the workplace ${ }^{[38]}$. The goal of these studies is to alleviate burnout (measured by lowering MBI scores). Intervention groups usually consist of relatively few participants, usually less than 100 . The training focuses on the ability of participants to cope with challenges as individuals, but there are also strategies for team-based responses. The root of this approach are three questions: can people learn coping skills? Can they apply this learning to the workplace? Will new coping styles affect burnout?

From the perspective of environment, paying attention to the work environment and the people in the work environment is very essential for the intervention to deal with burnout ${ }^{[26]}$. This suggests that the most effective intervention is to combine changes in management practices with the above educational interventions. Management interventions are necessary to change any of the six areas of working life, but it is not enough unless educational interventions convey the necessary individual skills and attitudes. Whether it is changing the environment or the individuals, effective change will occur only when the both develop in an integrated manner. The acquaintance of the six areas of work and life broadens the selection range of organizational intervention. For example, instead of focusing on interventions in overburdened areas (such as teaching people how to cope with overloading, how to reduce work or how to relax), it might be more effective to focus on other mismatched areas. If people pay attention to their work, feel that they are doing something important, or feel their efforts are well rewarded, they may be able to bear more work load, so interventions can be carried out by targeting at these areas of value and reward.

\section{Conclusion}

This review summarized the concept, impact of job burnout on nursing staff, current situation of job burnout of nursing profession at home and abroad, influencing factors, evaluation tools as well as improvement measures, and then the current situation of job burnout of nursing profession was introduced in detail.

However, the research on job burnout also has some shortcomings. At present, most of the researches on job burnout of nurses are investigative studies, such as interviews, questionnaires as well as online surveys. There is a serious lack of experimental studies, such as the intervention of nurses with job burnout and the understanding of the actual impact of various factors on individual nurses, which can better provide a clear direction for the solutions to nurses' job burnout.

In addition, there is a lack of cross-sectional study among different areas: such as the research on the horizontal comparison between grade a class 3 hospitals and other hospitals, inland and coastal cities, first-tier cities and other cities. Due to cultural differences of different areas, different hospital systems and economic level, whether will the differences between these regions have different influences on nurses' job burnout? After considering these factors, job burnout of nurses can be better understood from many aspects, and different focuses and solutions can be proposed to solve the problem of nurses' job burnout in different regions.

It is hoped that there will be more researches on nurses' job burnout in the future, providing more methods to solve or alleviate the current situation of nursing job burnout!

\section{REFERENCES}

[1] FREUDENBERGER H J. Staff Burn-Out [J]. Journal of Social Issues, 1974, 30(1): 159-65.

[2] MASLACH C, JACKSON S E J J O O B. The measurement of experienced burnout [J]. 1981, 2(2): 99-113.

[3] JEF A, VERONIQUE D G, STAN M. The impact of traumatic events on emergency room nurses: findings from a questionnaire survey $[\mathrm{J}]$. International Journal of Nursing Studies, 2012, 49(11): 1411-22.

[4] JANSSON-FRÖJMARK M, LINDBLOM K. Is There a Bidirectional Link Between Insomnia and Burnout? A Prospective Study in the Swedish Workforce [J]. International Journal of Behavioral Medicine, 2010, 17(4): 306-13.

[5] LEAPE L L, SHORE M F, DIENSTAG J L, et al. Perspective: a culture of respect, part 1: the nature and causes of disrespectful behavior by physicians [J]. Academic Medicine Journal of the Association of American Medical Colleges, 2012, 87(7): 845-52. 
[6] AHOLA K, HONKONEN T, PIRKOLA S, et al. Alcohol dependence in relation to burnout among the Finnish working population [J]. Addiction (Abingdon, England), 2006, 101(10): 1438-43.

[7] BRAND S, BECK J, HATZINGER $M$, et al. Associations between satisfaction with life, burnout-related emotional and physical exhaustion, and sleep complaints $[\mathrm{J}]$. The world journal of biological psychiatry : the official journal of the World Federation of Societies of Biological Psychiatry, 2010, 11(5): 744-54.

[8] AHOLA K, HONKONEN T, ISOMETSA E, et al. The relationship between job-related burnout and depressive disorders--results from the Finnish Health 2000 Study [J]. Journal of affective disorders, 2005, 88(1): 55-62.

[9] AHOLA K, PULKKI-RABACK L, KOUVONEN $\mathrm{A}$, et al. Burnout and behavior-related health risk factors: results from the population-based Finnish Health 2000 study [J]. Journal of occupational and environmental medicine, 2012, 54(1): 17-22.

[10] AGHILINEJAD M, SADEGHI Z, ABDULLAH $A$, et al. Role of occupational stress and burnout in prevalence of musculoskeletal disorders among embassy personnel of foreign countries in iran $[\mathrm{J}]$. Iranian Red Crescent medical journal, 2014, 16(5): e9066.

[11] Du Yanqiu, Wang Wenjun, Gu huaiting, et al. The relationship between physical and mental health and job burnout of grassroots public health personnel $[\mathrm{J}]$. Journal of Taishan Medical College, 2013, 34 (10): 733-6

[12] Sun Xiaojie. Analysis of job burnout status and influencing factors of grassroots and public health personnel $[\mathrm{J}]$. China health policy research, 2012, 5 (3): 26-31

[13] Wang Aiwu, Wu Chunming. Effect of job burnout on immune function of nurses $[\mathrm{J}]$. Journal of traditional Chinese medicine management, 2010, 18 (10): 945-6

[14] Xu Wenling. Research on the correlation between job burnout and mental health of nurses [J]. World's latest medical information abstract, 2017, 47):

[15] Gao Caiyun. The influence of job burnout on nursing work $[\mathrm{J}]$. Clinical medicine practice, 2008, 17 (4): $294-5$

[16] Xiao Xiaoling. A study on nurses' sense of occupational benefit and its influence on job burnout [J]. China nursing management, 2014, 14 (1): 56-60

[17] Duan Yinglong, Wu Xiaoxia, Zhong Zhuqing, et al. A study on the influence of nurses' professional identity and burnout on turnover intention $[\mathrm{J}]$. China nursing management, 2017, 17 (3): 368-73[18] LUSINE P, CLARKE S P, MARY F, et al. Nurse burnout and quality of care: cross-national investigation in six countries [J]. Research in Nursing \& Health, 2010, 33(4): 288-98.

[19] TOURIGNY L, BABA V V, WANG X. Burnout and depression among nurses in Japan and China: the moderating effects of job satisfaction and absence [J]. International Journal of Human Resource Management, 2010, 21(15): 2741-61

[20] GÄRTNER F R, NIEUWENHUIJSEN K, DIJK F $\mathrm{J} \mathrm{H} \mathrm{V}$, et al. The impact of common mental disorders on the work functioning of nurses and allied health professionals: A systematic review [J]. International Journal of Nursing Studies, 2010, 47(8): 1047-61.

[21] AIKEN L H, SLOANE D M, SEAN C, et al. Importance of work environments on hospital outcomes in nine countries [J]. Int J Qual Health Care, 2011, 23(4): 357-64.

[22] APIRADEE N, WICHIT S, WIPADA K, et al. Impact of nurse work environment and staffing on hospital nurse and quality of care in Thailand [J]. Journal of Nursing Scholarship, 2011, 43(4): 426-32.

[23] COLFF J J, VAN DER, SEBASTIAAN R. Burnout of registered nurses in South Africa [J]. Journal of Nursing Management, 2014, 22(5): 630-42.

[24] FUENTE C A D L, CRISTINA V, CONCEPCIÓN $\mathrm{S} \mathrm{L}$, et al. Risk factors and prevalence of burnout syndrome in the nursing profession $[\mathrm{J}]$. International Journal of Nursing Studies, 2015, 52(1): 240-9.

[25] Liang Xiangcui, Feng Xinglin. Research status of job burnout of nursing staff in China [J]. China nursing management, 2017, 17 (11): 1517

[26] AWA W L, PLAUMANN M, WALTER U. Burnout prevention: a review of intervention programs [J]. Patient education and counseling, 2010, 78(2): 184-90.

[27] MASLACH C, JACKSON S E. The Measurement of Experienced Burnout $[\mathrm{J}]$. Journal of Organizational 
Behavior, 1981, 2(2): 99-113.

[28] MASLACH C E, JACKSON SE, EDITOR; , LEITER MP, EDITOR. (EDS). Maslach Burnout Inventory manual, 3rd ed Palo Alto [M]. Consulting Psychologists Press, 1996.

[29] MASLACH C L M, SCHAUFELI WB. MEASURING BURNOUT IN: COOPER CL, EDITOR; , CARTWRIGHT S, EDITOR. (EDS). The Oxford handbook of organizational well-being. Oxford [M]. Oxford University Press, 2009.

[30] FREUDENBERGER H J, RICHELSON G. Burn-out: The high cost of high achievement [M]. Bantam Books, 1981.

[31] MALAKH-PINES A, ARONSON E, KAFRY D. Burnout: From tedium to personal growth [M]. Free Pr, 1981.

[32] FELDT T, RANTANEN J, HYVONEN K, et al. The 9-item Bergen Burnout Inventory: factorial validity across organizations and measurements of longitudinal data [J]. Industrial health, 2014, 52(2): 102-12.

[33] HALBESLEBEN J R, DEMEROUTI E. The construct validity of an alternative measure of burnout: Investigating the English translation of the Oldenburg Burnout Inventory [J]. Work \& Stress, 2005, 19(3): 208-20.

[34] SHIROM A, MELAMED S. A comparison of the construct validity of two burnout measures in two groups of professionals [J]. International journal of stress management, 2006, 13(2): 176.

[35] KRISTENSEN T S, BORRITZ M, VILLADSEN $\mathrm{E}$, et al. The Copenhagen Burnout Inventory: A new tool for the assessment of burnout [J]. Work \& Stress, 2005, 19(3): 192-207.

[36] GIL-MONTE P R, FIGUEIREDO-FERRAZ H. Psychometric properties of the 'Spanish burnout inventory' among employees working with people with intellectual disability $[\mathrm{J}]$. Journal of intellectual disability research : JIDR, 2013, 57(10): 959-68.

[37] BORGOGNI L, CONSIGLIO C, ALESSANDRI $\mathrm{G}$, et al. "Don't throw the baby out with the bathwater!" Interpersonal strain at work and burnout [J]. European Journal of Work and Organizational Psychology, 2012, 21(6): 875-98.

[38] DE BEER L T, PIENAAR J, ROTHMANN S, JR. Work overload, burnout, and psychological ill-health symptoms: a three-wave mediation model of the employee health impairment process $[\mathrm{J}]$. Anxiety, stress, and coping, 2016, 29(4): 387-99. 